NASA/CR—2004-213110

\title{
Computed Linear/Nonlinear Acoustic Response of a Cascade for Single/Multi Frequency Excitation
}

M. Nallasamy

QSS Group, Inc., Cleveland, Ohio

R. Hixon

University of Toledo, Toledo, Ohio

S. Sawyer

University of Akron, Akron, Ohio 
Since its founding, NASA has been dedicated to the advancement of aeronautics and space science. The NASA Scientific and Technical Information (STI) Program Office plays a key part in helping NASA maintain this important role.

The NASA STI Program Office is operated by Langley Research Center, the Lead Center for NASA's scientific and technical information. The NASA STI Program Office provides access to the NASA STI Database, the largest collection of aeronautical and space science STI in the world. The Program Office is also NASA's institutional mechanism for disseminating the results of its research and development activities. These results are published by NASA in the NASA STI Report Series, which includes the following report types:

- $\quad$ TECHNICAL PUBLICATION. Reports of completed research or a major significant phase of research that present the results of NASA programs and include extensive data or theoretical analysis. Includes compilations of significant scientific and technical data and information deemed to be of continuing reference value. NASA's counterpart of peerreviewed formal professional papers but has less stringent limitations on manuscript length and extent of graphic presentations.

- TECHNICAL MEMORANDUM. Scientific and technical findings that are preliminary or of specialized interest, e.g., quick release reports, working papers, and bibliographies that contain minimal annotation. Does not contain extensive analysis.

- CONTRACTOR REPORT. Scientific and technical findings by NASA-sponsored contractors and grantees.
- CONFERENCE PUBLICATION. Collected papers from scientific and technical conferences, symposia, seminars, or other meetings sponsored or cosponsored by NASA.

- SPECIAL PUBLICATION. Scientific, technical, or historical information from NASA programs, projects, and missions, often concerned with subjects having substantial public interest.

- TECHNICAL TRANSLATION. Englishlanguage translations of foreign scientific and technical material pertinent to NASA's mission.

Specialized services that complement the STI Program Office's diverse offerings include creating custom thesauri, building customized databases, organizing and publishing research results ... even providing videos.

For more information about the NASA STI Program Office, see the following:

- Access the NASA STI Program Home Page at http://www.sti.nasa.gov

- E-mail your question via the Internet to help@sti.nasa.gov

- Fax your question to the NASA Access Help Desk at 301-621-0134

- Telephone the NASA Access Help Desk at 301-621-0390

- Write to:

NASA Access Help Desk

NASA Center for AeroSpace Information 7121 Standard Drive

Hanover, MD 21076 
NASA/CR-2004-213110

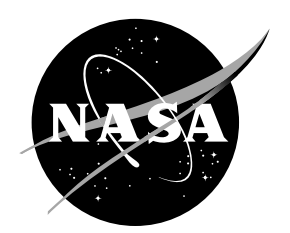

\section{Computed Linear/Nonlinear Acoustic Response of a Cascade for Single/Multi Frequency Excitation}

M. Nallasamy

QSS Group, Inc., Cleveland, Ohio

R. Hixon

University of Toledo, Toledo, Ohio

S. Sawyer

University of Akron, Akron, Ohio

Prepared for the

Tenth Aeroacoustics Conference

cosponsored by the American Institute of Aeronautics and Astronautics and the Confederation of European Aerospace Societies

Manchester, United Kingdom, May 10-12, 2004

Prepared under Contract NAS3-00145

National Aeronautics and

Space Administration

Glenn Research Center 


\section{Acknowledgments}

The authors would like to thank Dr. Envia for his many helpful comments and encouragements.

Available from

NASA Center for Aerospace Information 7121 Standard Drive

Hanover, MD 21076
National Technical Information Service 5285 Port Royal Road Springfield, VA 22100

Available electronically at http:/ /gltrs.grc.nasa.gov 


\title{
Computed Linear/Nonlinear Acoustic Response of a Cascade for Single/Multi Frequency Excitation
}

\author{
M. Nallasamy \\ QSS Group, Inc. \\ Cleveland, Ohio 44135 \\ R. Hixon \\ University of Toledo \\ Toledo, Ohio 43606 \\ S. Sawyer \\ University of Akron \\ Akron, Ohio 44325
}

\begin{abstract}
Summary
This paper examines mode generation and propagation characteristics of a 2-D cascade due to incident vortical disturbances using a time domain approach. Full nonlinear Euler equations are solved employing high order accurate spatial differencing and time marching techniques. The solutions show the generation and propagation of mode orders that are expected from theory. Single frequency excitations show linear response over a wide range of amplitudes. The response for multi-frequency excitations tend to become nonlinear due to interaction between frequencies and self interaction.
\end{abstract}

\section{Introduction}

The gust-cascade interaction problem has been studied extensively using semi-analytical and numerical approaches. These techniques mostly employ a frequency domain approach, examining one frequency at a time. With the availability of parallel processing algorithms, time domain approach has become feasible for gust-cascade interaction study. A time domain approach has the advantage that all harmonics of interest can be extracted from one solution and thus, may be able to mimic the real flow more closely. Also, linear/nonlinear regimes, self interaction, and multi-frequency interaction may be explored. In the nonlinear range, energy transfer between different frequencies (harmonics) occur, and such energy transfers are easily handled in a time domain approach.

The 2-D cascade considered here is an unrolled section at a radial station of a modern high speed turbofan stator (fig. 1), for which flow and noise data are available. The incident gust is the periodic mean wake impinging on the stator vanes. The measured wake is represented using a Fourier series which includes only three harmonics of the blade passing frequency (BPF). The acoustic response of the cascade for this specified gust is studied employing a time domain approach. The full nonlinear Euler equations are solved employing high order accurate spatial differencing schemes, time marching schemes, and boundary conditions.

In an earlier study (ref. 1), the acoustic response of the above 2-D cascade was examined for single and two frequency excitations. It was found that the acoustic response is linear for single frequency excitations. In the case of two frequency excitations $(\mathrm{BPF}+2 \mathrm{BPF})$, the response was linear only when the BPF amplitude was small. For higher amplitudes of BPF, the response was nonlinear due to self interaction. The results also showed that the response was linear for equal excitation amplitudes of the two harmonics. When the amplitudes of the two harmonics are unequal and BPF amplitude is high, the 
self interaction of BPF (which is cutoff for the geometry) influences the amplitude of the propagating 2BPF mode in a significant way, both in the inflow and outflow regions.

The 2-D gust-cascade interaction was one of the problems in the Fourth Computational Aeroacoustics Workshop on Benchmark Problems ${ }^{2}$. There, the acoustic response was sought for excitation at 3 harmonics (BPF, 2BPF, and 3BPF). The BPF amplitude of excitation was specified such that acoustic response would be in the linear range. While BPF response should show an exponential decay (cutoff), the propagating mode amplitudes at $2 \mathrm{BPF}$ and $3 \mathrm{BPF}$ are of particular interest. At $2 \mathrm{BPF}$, the circumferential mode order $m=-5$ is a well cuton mode and propagates in the inflow and outflow regions (see fig. 2 for definition of these regions) without the influence of BPF. At 3BPF, the theory predicts propagation of two circumferential mode orders, $m=6$ and $m=-21$. While mode $m=6$ is well cuton, mode $m=-21$ is very close to cutoff. The flow solution obtained by the present time domain approach with the downstream boundary located at $x=1.5$ (as specified in the problem, see fig. 2) showed that the $m=-21$ mode propagates upstream as expected but at the outflow shows a slow decay and appear to propagate only near the end of the computational domain. This was examined further by obtaining a fine grid solution which also produced mode propagation characteristics as that of the coarse grid solution.

Next, a grid stretched gradually in the $x$-direction (fig. 3) of the outflow region to $x=12.85$ was used so that no reflected component, if any (from the downstream boundary) can influence the mode propagation characteristics, in particular that of the mode close to cutoff $m=-21$. The solution obtained with this stretched grid, showed that at $3 \mathrm{BPF}, m=-21$ mode also propagates in the inflow as well as outflow regions.

In the present paper, the stretched grid is used to study the linear/nonlinear behavior of single and multi-frequency excitations. The acoustic responses obtained over a range of amplitudes of excitations are presented and discussed.

\section{2-D Cascade Problem}

A sketch of the gust-cascade problem is shown in figure 1 . The velocity triangle at the inflow shows the gust (representing the wake from the rotor blades) in the direction of relative flow velocity $\left(W_{\infty}\right)$ at an angle $\beta$ to the $x$-axis. The direction of tangential velocity $(\Omega r)$ is in the positive $y$-direction as indicated resulting in the axial velocity $\left(V_{\infty}\right)$ making an angle $\alpha$ to the $x$-axis. The cascade has a gap-to-chord ratio of $\mathrm{d} / \mathrm{c}=2 / 3$ with the inflow and outflow planes located at $x=3 / 2 c$, where $c$ is the vane chord, and $d$ is the vane gap. The mean flow conditions at the inflow and outflow planes are given as:

Inflow: $P_{i}=1, T_{i}=1$, and $\alpha_{i}=36^{\circ}$

Outflow: $p_{o} / P_{i}=0.92$

where $P_{i}$ and $T_{i}$ are the normalized mean stagnation pressure and stagnation temperature respectively. $\alpha_{i}$ is the mean flow angle and $p_{o}$ is the mean static pressure at the outflow plane. The inflow periodic wake disturbance is described at the inflow plane as:

$$
\begin{gathered}
\vec{u}_{g}^{\prime}(y, t)=\left\{a_{1} \cos \left(k_{y} y-\omega t\right)+a_{2} \cos \left(2\left(k_{y} y-\omega t\right)\right)+a_{3} \cos \left(3\left(k_{y} y-\omega t\right)\right)\right\} \hat{e}_{\beta} \\
\rho_{g}^{\prime}(y, t)=0, p_{g}^{\prime}(y, t)=0 \\
\hat{e}_{\beta}=\cos (\beta) \hat{e}_{x}-\sin (\beta) \hat{e}_{y}, \beta=44^{\circ} \\
\omega=3 \pi / 4, k_{y}=11 \pi / 9, a_{1}=0.005, a_{2}=0.003, a_{3}=0.0007
\end{gathered}
$$


where $\omega$ is the fundamental reduced frequency, $k_{y}$ is the transverse wavenumber, and $a_{i}$ s are the gust harmonic amplitudes.

The frequency is normalized by the chord divided by the ambient speed of sound, wavenumber is normalized by the vane chord, and gust amplitudes are normalized by the ambient speed of sound. The harmonic amplitudes of excitation $a_{1}$ (at BPF), $a_{2}$ (at 2BPF) and $a_{3}$ (at 3BPF) have been varied to study the nonlinearities associated with the high amplitudes and multi-frequency excitations.

\section{Governing Equations}

The full nonlinear Euler equations governing the 2-D cascade flow are solved in the present investigation. In Cartesian coordinates these equations are written as:

$$
\frac{\partial Q}{\partial t}+\frac{\partial E}{\partial x}+\frac{\partial F}{\partial y}=0
$$

where

$$
\begin{gathered}
Q=\left[\begin{array}{l}
\rho \\
\rho u \\
\rho v \\
E
\end{array}\right] \\
E=\left[\begin{array}{l}
\rho u \\
\rho u^{2}+p \\
\rho u v \\
u(E+p)
\end{array}\right] \\
F=\left[\begin{array}{l}
\rho v \\
\rho u v \\
\rho v^{2}+p \\
v(E+p)
\end{array}\right]
\end{gathered}
$$

and

$$
p=(\gamma-1)\left\{E-\frac{1}{2} \rho\left(u^{2}+v^{2}\right)\right\}
$$

These equations are cast in generalized curvilinear coordinates employing the chain rule formulation as:

$$
\frac{\partial Q}{\partial \tau}+\frac{\partial \xi \partial E}{\partial x \partial \xi}+\frac{\partial \eta \partial E}{\partial x \partial \eta}+\frac{\partial \xi \partial F}{\partial y \partial \xi}+\frac{\partial \eta \partial F}{\partial y \partial \eta}=0
$$




\section{Solution Procedure}

The full nonlinear time dependent Euler equations governing the 2-D cascade flow are solved employing a parallel computational aeroacoustic (CAA) code developed by Hixon et al. described in part in reference 3. Some details of the computational techniques are discussed in references 4 and 5 . The flow equations written in chain-rule curvilinear form are solved using a prefactored sixth-order compact scheme for spatial differencing. The time marching uses a $2 \mathrm{~N}$ Storage fourth-order nonlinear extension of Hu's 5-6 Low Dissipation and Dispersion Runge-Kutta (LDDRK) scheme. ${ }^{6,7}$ An explicit 10th order constant coefficient artificial dissipation ${ }^{8}$ is used at every stage of the Runge-Kutta solver to dissipate unresolved waves. On the airfoils, the time derivative of the velocity normal to the wall is set to zero.

At the inflow and outflow planes Giles nonreflecting boundary conditions ${ }^{9}$ for the unsteady flow are implemented. The characteristics are defined as in reference 9 for the inflow and outflow boundaries. While fourth order boundary conditions are used at the inflow, second order boundary conditions are employed at the out flow (fourth order boundary condition at the outflow was found to produce numerical instabilities). While computing the derivatives of the characteristics, the gust components are subtracted at the inflow boundary. Once the time derivatives of the velocity components are computed, the gust components are added to them. Changes in the conserved variables as used in the code are then computed at the inflow and outflow boundaries.

The specified mean flow boundary conditions have to be satisfied at the inflow and outflow boundaries. To apply the mean flow boundary condition (MFBC), the mean flow is directly computed at the boundaries as the flow evolves. The time derivative of the flow at the boundary is written as a sum of three components:

$$
\left(Q_{t}\right)_{\text {boundary }}=\left(Q_{t}\right)_{\mathrm{MFBC}}+\left(Q_{t}\right)_{\text {gust }}+\left(Q_{t}\right)_{\text {non-reflective }}
$$

The method of evaluating $\left(Q_{t}\right)_{\mathrm{MFBC}}$ is discussed in detail in reference 10 . This solution procedure has been successively used to study the gust response and the influence of steady loading. ${ }^{11,12}$

\section{Computational Domain and Numerical Solution}

For the cascade configuration considered here the blade passing frequency is cutoff, at 2BPF the propagating mode is $m=-5$, and at 3BPF the propagating modes are $m=6$ and $m=-21$ (ref. 2). The grid used in this study is a stretched grid (fig. 3) to dissipate the outgoing waves at large distances in the downstream direction. The grid has 8 blocks with a total of 9506 grid points in each flow passage. Care is taken to increase the grid resolution in the leading edge, trailing edge, and wake regions. In the current solution procedure, 27 passages are solved and a periodic boundary condition in the $y$-direction is specified. With the specified gust amplitude, the solution is run until periodicity in pressure is achieved on the airfoil and on the inflow and outflow boundaries. The solution was run up to 235 periods so that change in circumferential mode amplitudes between successive periods is within one percent. Once the periodic solution is established, the solution is processed to obtain the acoustic response of the propagating modes at 2 nd and 3rd harmonics.

\section{Joint Temporal-Spatial Transform}

The cascade unsteady flow solution as a function of time is known over a specified period. The acoustic pressure response is not only harmonic in time, but also periodic in the tangential direction, $y$. From the known acoustic pressure $p$ as a function of $(x, y, t)$, the acoustic mode amplitude $P$ as a function of $(x, m, n)$, where $m$ is the circumferential mode order and $n$ is the harmonic order, is written ${ }^{2}$ as 


$$
P(x, m, n)=\frac{2}{N N_{\Delta t}} \sum_{l=0}^{N-1} \sum_{j=0}^{N_{\Delta t}-1} p\left(x, y_{l}, t_{j}\right) e^{-2 \pi i n j / N_{\Delta t}} e^{-2 \pi i m l / N}
$$

where, $\Delta t$ is the time between samples, $N_{\Delta t}$ is the number of samples over interval $T$, frequency $f=n / T$, and $n=0,1,2, \ldots .\left(N_{\Delta t}-1\right) / 2$ is the harmonic number. $N$ is the number of points in the tangential direction. $m$ is the spatial (circumferential) mode order, $-N / 2<m<(N / 2-1)$.

\section{Results and Discussions}

The cascade acoustic response for a vortical disturbance is studied using the time domain approach. The incident vortical disturbance includes three harmonics. The acoustic response of the propagating modes at 2nd and 3rd harmonics for single and multi-frequency excitations are examined.

\section{Propagating Modes}

For the cascade-gust interaction problem considered here, theory predicts propagation of $m=-5$ mode at 2BPF and two modes $m=6$ and $m=-21$ at 3BPF. However, $m=-21$ mode is very close to cutoff. The initial grid (fig. 2) used for the computation had the computational domain in the $x$-direction as specified in the benchmark problem, ${ }^{2}$ from $x=-1.5$ to $x=1.5$. The solution obtained with this grid showed propagation of all the expected modes at the inflow. At the outflow, only $m=-5$ and 6 modes propagated while $m=-21$ mode was found to decay slowly. It was suspected that the small reflections from the downstream boundary with the current implementation of the nonreflecting boundary conditions may contribute to the observed behavior of the mode $m=-21$. To avoid those reflections, the grid was stretched in the downstream direction to $x=12.85$ (fig. 3). The solution obtained with this grid for the excitation amplitudes specified by the benchmark problem showed that the mode $m=-21$ also clearly propagated as expected from theory. The propagating mode amplitudes from the two solutions are compared in figure 4 for the inflow and outflow regions. At the inflow, the two solutions produce nearly similar amplitudes of the three propagating modes. At the outflow, $m=-5$ and $m=6$ mode amplitudes are the same for the two solutions. The effect of small reflections on the axial variation of 2BPF amplitude is not seen with the stretched grid solution and $m=-21$ mode clearly propagates in the downstream direction.

Figure 5 shows the complex amplitude of the propagating modes in the inflow and outflow regions. A perfectly propagating wave would appear as a circle in such a plot. At 2BPF (fig. 5(a)), $m=-5$ mode propagates well in the upstream and downstream directions. In figure 5(b), complex amplitudes of the two modes $(m=6$ and -21$)$ are shown for the inflow and outflow regions and they clearly show well propagating modes. Hence in the present study, the stretched grid is used to examine the linear/nonlinear behavior of single/multi frequency excitations.

The pressure distributions on the airfoil surface, obtained with regular and stretched grids, for the 3rd harmonic excitation $\left(a_{3}=0.0007\right)$ are shown in figure $5(\mathrm{c})$. The plots show substantial differences in pressure along the airfoil chord between the two solutions. While differences in magnitude are seen through the entire chord, the characteristics are different only near the leading edge region. Even here the leading edge peaks are nearly identical. But beyond the leading edge peak, loading difference occurs. It appears that this change in loading near the leading edge region is instrumental in changing the downstream propagation characteristics of $m=-21$ mode. 


\section{Single Frequency Excitation: Effect of Amplitude of Excitation}

Acoustic response characteristics of the cascade, for single frequency excitation is first explored. Figure 6(a) shows amplitudes of the propagating mode $m=-5$ for 2BPF excitation in the upstream and downstream directions. When the excitation amplitude is increased 10 times to $a_{2}=0.03$, the $2 \mathrm{BPF}$ response also increases 10 times as shown in the figure. The dashed line represent the response for the excitation amplitude $\mathrm{a}_{2}=0.003$ multiplied by a factor of 10 . The linearity of the response for $2 \mathrm{BPF}$ excitation is clearly exhibited.

For 3BPF excitation, a similar increase in excitation amplitude by a factor of 10 to 0.007 (from the original 0.0007) is shown to increase amplitudes of the propagating modes $m=6$ (fig. 6(b)) and $m=-21$ by the same amount (fig. 6(c)) in inflow as well as outflow regions. Again, the dashed lines represent the response for the excitation amplitude of $a_{3}=0.0007$ multiplied by a factor of 10 . The acoustic response of the cascade for $3 \mathrm{BPF}$ is clearly seen to be linear.

Figure 7 shows a plot of excitation amplitude against the acoustic response for upstream and downstream propagating waves. One interesting feature to note is that in the downstream direction for equal amplitudes of excitation, 3BPF mode $m=-21$ has higher response amplitudes than that of the 2BPF $(m=-5)$ which was the dominant one for the original amplitudes of excitation specified in the problem.

\section{Multi-Frequency Excitation}

Next, the amplitudes of excitation in all three harmonics are specified to be 10 times the original amplitude. Figure 8 shows response amplitudes of the propagating modes for three-frequency excitation, $a_{1}=0.05, a_{2}=0.03$, and $a_{3}=0.007$. It is immediately seen that response for multi-frequency excitations are substantially different. At $2 \mathrm{BPF}, m=-5$ is well propagating at the inflow with a higher amplitude compared to $2 \mathrm{BPF}$ alone excitation. At the outflow, while the amplitude is much different, it appears to depart from linear behavior (fig. 8(a)).

At 3BPF, in the flow region, $m=6$ mode amplitude is smaller while $m=-21$ mode amplitude is higher compared to 3BPF alone excitation. At the outflow an opposite trend is observed, i.e., the amplitude of $m=6$ mode is higher and $m=-21$ mode is lower than that of 3BPF only excitation, and appears highly nonlinear (fig. 8(b)). The modification of propagating mode amplitudes and the departure from linear behavior appear to stem from self interaction of BPF.

To examine self interaction effects further, keeping the excitation amplitudes of 2BPF at 0.003 and $3 \mathrm{BPF}$ at 0.0007 , only the BPF amplitude of excitation is varied. The results of this study are shown in figure 9. It is seen that increase/decrease of the each propagating mode follows the pattern described above with reference to figure 8 . But the departure from linearity starts to appear particularly at the outflow in all the propagating modes when the BPF amplitude of excitation is 0.02 . The departure from well propagating modes is shown in figure 10, where complex amplitudes of the downstream propagating modes are shown. It is more clearly seen with respect to modes $m=-5$ and $m=6$.

When the amplitudes of excitation of the first and second harmonic are kept equal and increased gradually, the characteristics of the propagating modes are quite different as shown in figure 11. At 2BPF, the mode $m=-5$ is well propagating and linear (fig. 11(a)) as would be expected since $a_{1}=a_{2}$. The 3BPF response amplitude undergoes complicated modifications due to self interaction and interaction between harmonics (frequencies). Also shown for comparison are the response amplitudes of single frequency excitation. Only upstream propagating $m=-21$ mode remains linear and shows monotonic increase in response with increasing $\mathrm{BPF}+2 \mathrm{BPF}$ excitation amplitude.

The linear behavior of 2BPF and departure from linear response of 3BPF are illustrated in figure 12, by the complex mode amplitudes of the propagating modes at the outflow region. At 2BPF mode $m=-5$ is clearly well propagating while at $3 \mathrm{BPF}, m=6$ shows first signs of departure from linear behavior of a well propagating mode. 


\section{Equal Amplitude Excitation}

When the amplitudes of excitation are equal, then the propagating modes are expected to remain linear and well propagating. This is illustrated for excitation amplitudes of $a_{1}=a_{2}=a_{3}$ in figure 13. Also shown are the response amplitudes for excitations with $a_{2}=a_{3}$ and $a_{1}=0$ (dashed lines). The results clearly show that equal amplitude excitations result in nearly linear response and $a_{1}$ has little influence on the propagating modes.

\section{Nonlinear Effects: Loading and Wakes}

The factors that initiate the nonlinear responses are explored in this section. Figure 14(a) shows the typical loading on airfoil surface for three harmonics of excitations. Although the first harmonic loading is high, the BPF modes are cutoff for this configuration. The magnitude of loading decreases for higher harmonics.

Next the 2BPF loading variations, for single frequency excitation, are examined. Figure 14(b) shows the loading for $2 \mathrm{BPF}$ excitation at $a_{2}=0.003$. Also shown are the $2 \mathrm{BPF}$ loading due to self interaction when excitation is at BPF and the amplitude is high. Loading for two amplitudes of excitation $a_{1}=0.015$ and $a_{1}=0.03$ are shown in the figure. It is seen that the character (shape) of the loading due to self interaction is different from that of the $2 \mathrm{BPF}$ alone excitation. Also, the loading due to self interaction due to BPF excitation with $a_{1}=0.03$ is higher than that of $2 \mathrm{BPF}$ alone excitation. This explains at least in part the high amplitudes of acoustic response when the amplitude of BPF excitation is increased (fig. 9).

Figure 14(c) shows the 2BPF loading for two frequency excitation (BPF+2BPF) compared with loading due to $2 \mathrm{BPF}$ only excitation. When the amplitudes of excitation are unequal, $a_{1} \neq a_{2}$, the character of loading is different from the loading at amplitudes of excitation in the linear range. For equal amplitudes of excitation, $a_{1}=a_{2}=0.03$, the character of the loading curve is similar to that of loading in the single frequency linear range excitation (at $a_{2}=0.003$ ). Hence, the change in character/shape of the loading curve is also an indication of departure from linear behavior. And, self interaction tends to change the nature of the loading curve.

The downstream propagating waves tend to depart from linearity at amplitudes lower than upstream propagating ones. This is due to the wake development behind the vane trailing edge. The thickness of the wake increases with increasing amplitude of excitation as illustrated in figure 15, which shows the vorticity contours in the wake region of airfoil trailing edge for three amplitudes of excitation.

\section{Concluding Remarks}

A time domain approach was employed to study the gust cascade interaction problem. In this approach, full nonlinear Euler equations are solved using high order accurate spatial differencing and time marching techniques. Single frequency and multi-frequency excitations were considered to examine linear/nonlinear effects. The results of single frequency excitations show linear response over a wide range of amplitudes. Multi frequency excitations show that interaction between frequencies and self interaction modify the $2 \mathrm{BPF}$ and $3 \mathrm{BPF}$ responses. The higher harmonic responses become non monotonic and eventually exhibit nonlinear behavior. A complicated nonlinear response of 3BPF is observed when

excitation amplitudes of BPF and $2 \mathrm{BPF}$ are equal. On the other hand, when the amplitudes of excitation at 
the three harmonics are equal, nearly linear behavior is retained. The change in characteristics of airfoil loading and increasing thickness of the wake behind the airfoil trailing edge appear to contribute to the observed nonlinear behavior. Actual measurements may include such nonlinear effects and the present approach may help in understanding such features. However, linearized Euler analysis ${ }^{13}$ has been shown to produce reasonably well the first two harmonics of rotor-stator interaction noise. The time domain approach will be used next to compute rotor-stator (3-D) interaction noise and compare with the experimental data. Such a study will clarify the influence of nonlinear effects on computed noise levels in annular cascades of interest.

\section{References}

1. Nallasamy, M., Hixon, R., Sawyer, D., and Dyson, R.W., “A time domain analysis of gust - cascade interaction noise," AIAA Paper 2003-3134, 2003.

2. Nallasamy, M. Hixon, R., Sawyer, D., and Dyson, R.W., "Category 3: Sound generation by interacting with a gust, problem 2: Cascade-gust interaction," Fourth Aeroacoustics Workshop on Benchmark Problems, 2003.

3. Hixon, R, Nallasamy, M. and Sawyer, S.S, "Parallelization strategy for an explicit computational aeroacoustic code," AIAA Paper 2002-2583, 2002.

4. Hixon, R, "Nonlinear comparison of high-order and optimized finite-difference schemes," Journal of Computational Fluid Dynamics, vol. 13, pp. 257-277, 2000.

5. Hixon, R, Shih, S.-H., Mankabadi, R.R., "Evaluation of boundary conditions for the gust-cascade problem," Journal of Propulsion and Power, vol. 16, pp. 72-78, 2000.

6. Hu, F.Q., Hussaini, M.Y. and Manthey, J., "Low-Dissipation and Dispersion Runge-Kutta Schemes for Computational Acoustics," Journal of Computational physics, vol. 124, pp. 121-133, 1996.

7. Stanescu, D. and Habashi, W.G., "2N-Storage Low Dissipation and Dispersion Runge-Kutta Schemes for Computational Acoustics," Journal of Computational Physics, vol. 143, pp. 674-681, 1998.

8. Kennedy, C.A. and Carpenter, M.H., "Several new numerical methods for compressible shear layer simulations," Applied Num. Math., Vol. 4, 1994, pp. 397-433.

9. Giles, M., "Nonreflecting boundary conditions for Euler equation calculations," AIAA Journal, Vol. 28, pp. 2050-2058, 1990.

10. Hixon, R., Nallasamy, M., Sawyer, D., and Dyson, R.W., "Mean flow boundary conditions for computational aeroacoustics," AIAA Paper 2003-3299, 2003.

11. Sawyer, S, Nallasamy, M., Hixon, R., and Dyson, R.W., "Computational aeroacoustic prediction of discrete frequency noise generated by rotor-stator interaction," AIAA Paper 2003-3268, 2003.

12. Sawyer, S, Nallasamy, M., Hixon, R., and Dyson, R.W., "The influence of steady loading on discretefrequency rotor-stator interaction noise," AIAA paper 2003-4419, 2003.

13. Verdon, J.M., "Linearized unsteady aerodynamic analysis of the acoustic response to wake/blade row interaction," NASA CR-210713, 2001. 

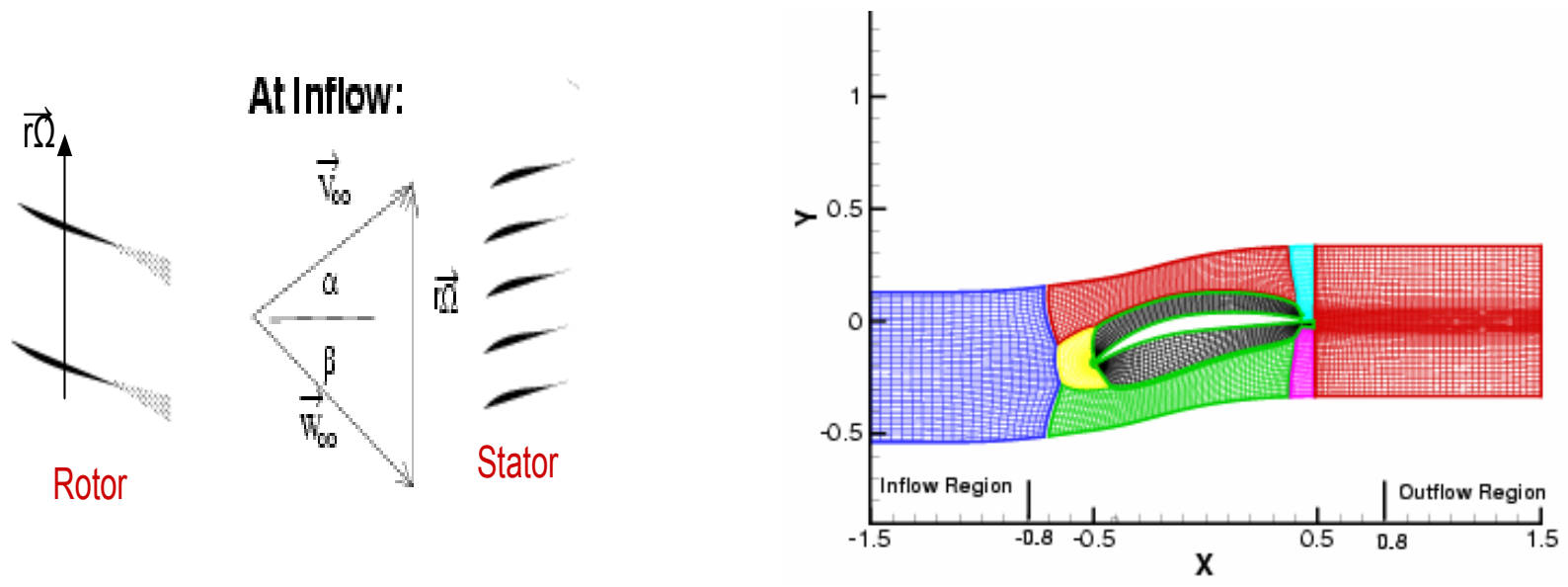

Figure 1. Gust-Cascade problem

Figure 2. Regular grid

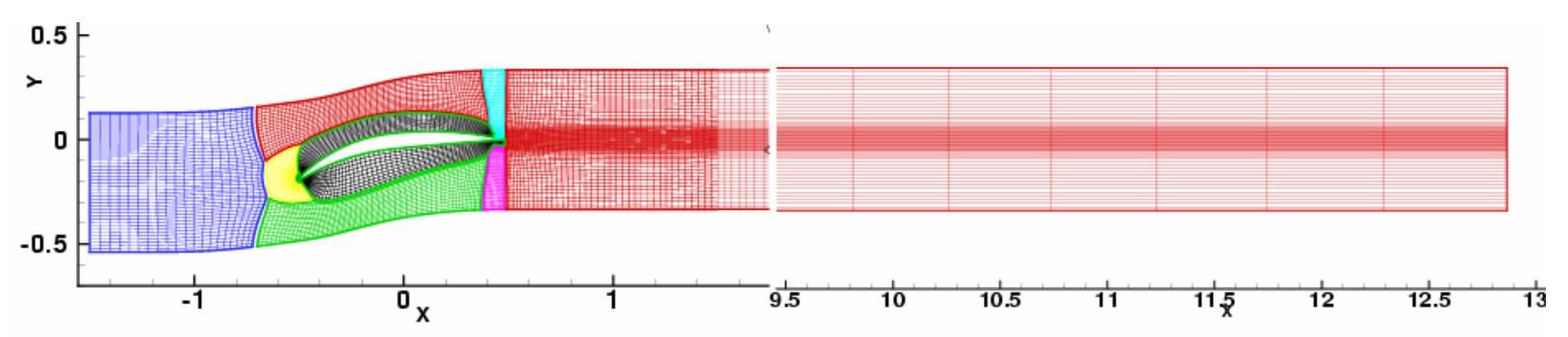

Figure 3. Stretched grid
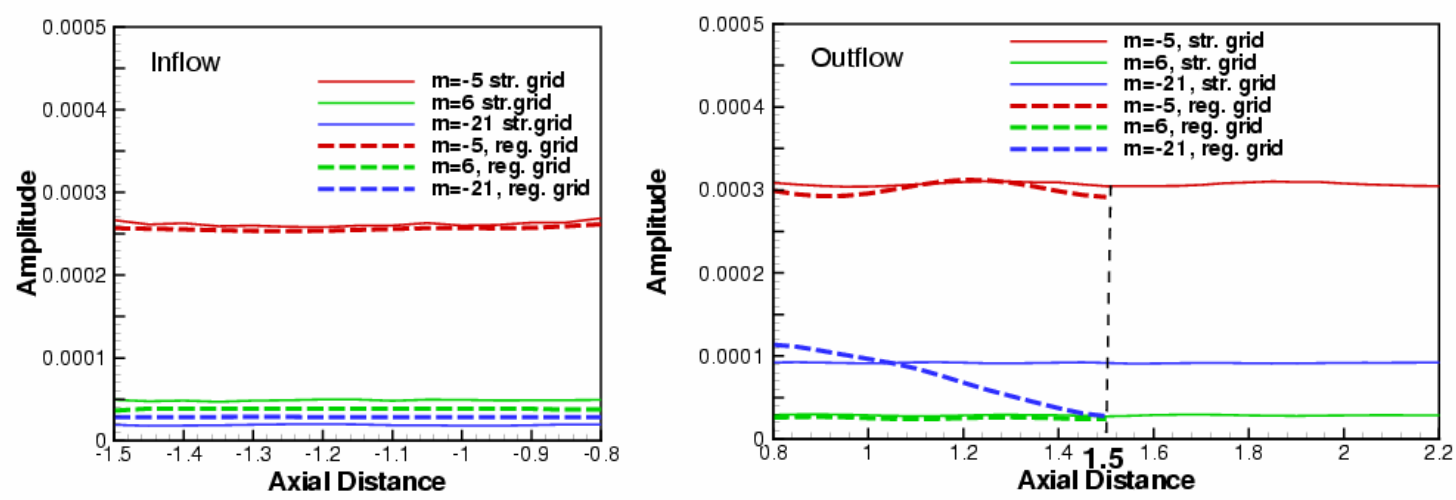

Figure 4. Amplitude of propagating modes: regular and stretched grid solutions 


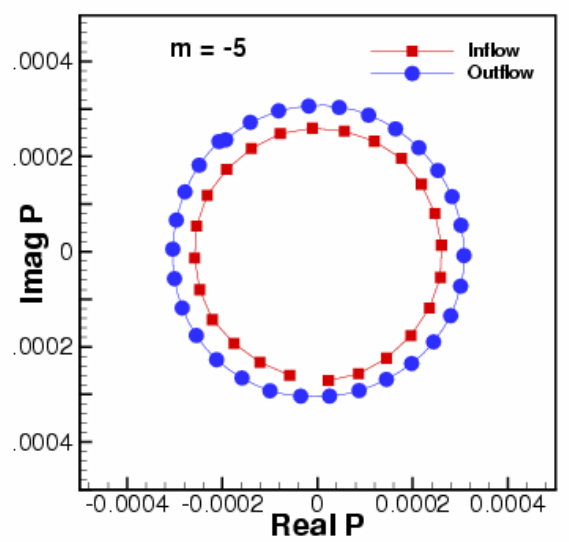

Figure 5(a). Complex pressure amplitudes of propagating modes at $2 \mathrm{BPF}$
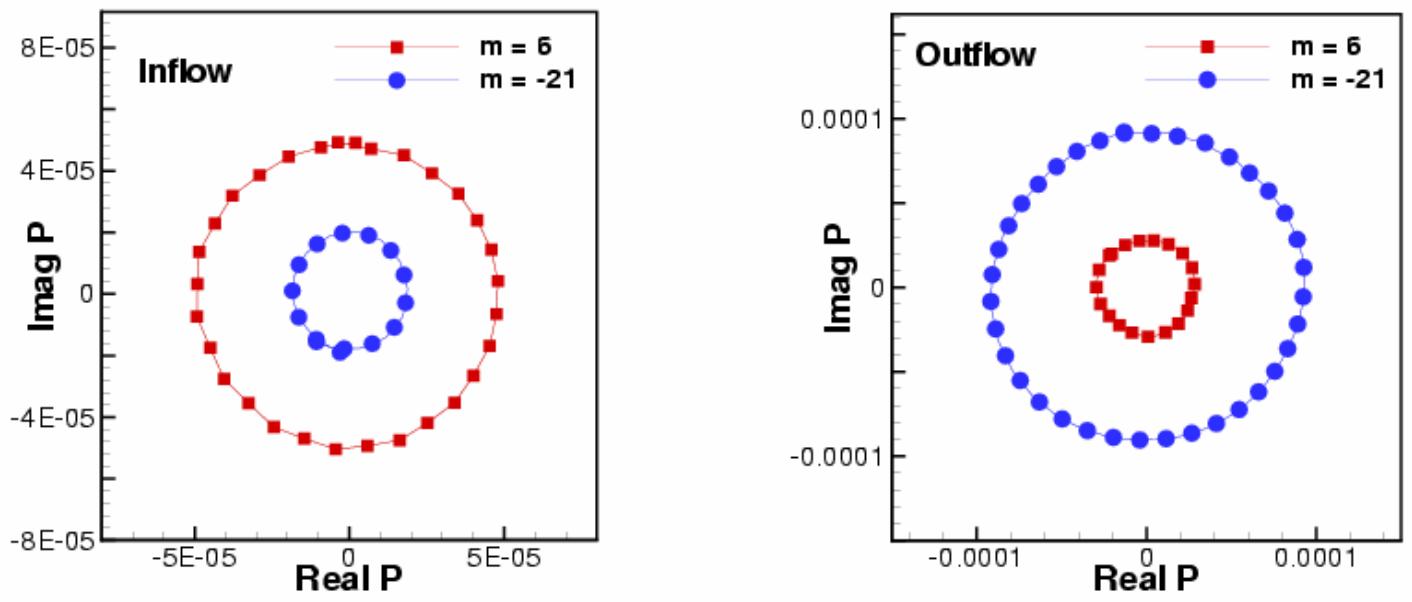

Figure 5(b). Complex pressure amplitudes of propagating modes at 3BPF

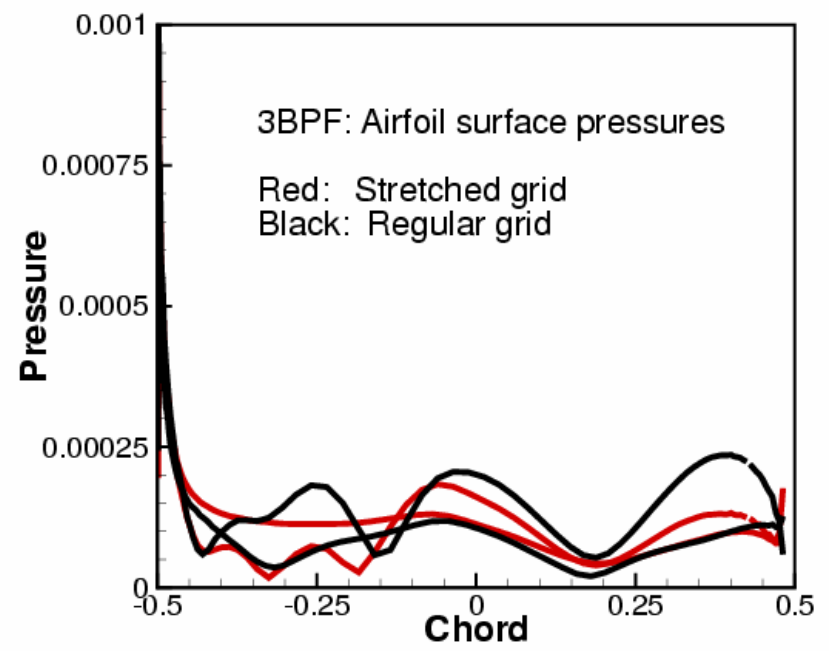

Figure 5(c). Airfoil surface pressure distribution at 3BPF 

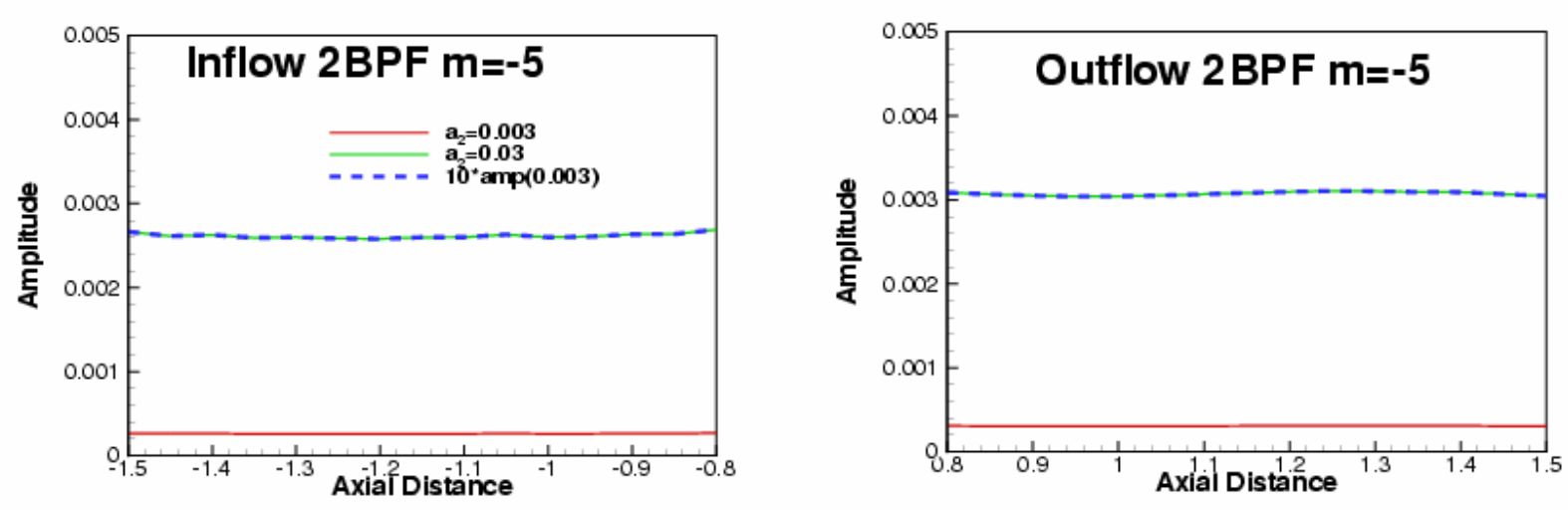

Figure 6(a). Single frequency excitation: linear behavior at 2BPF
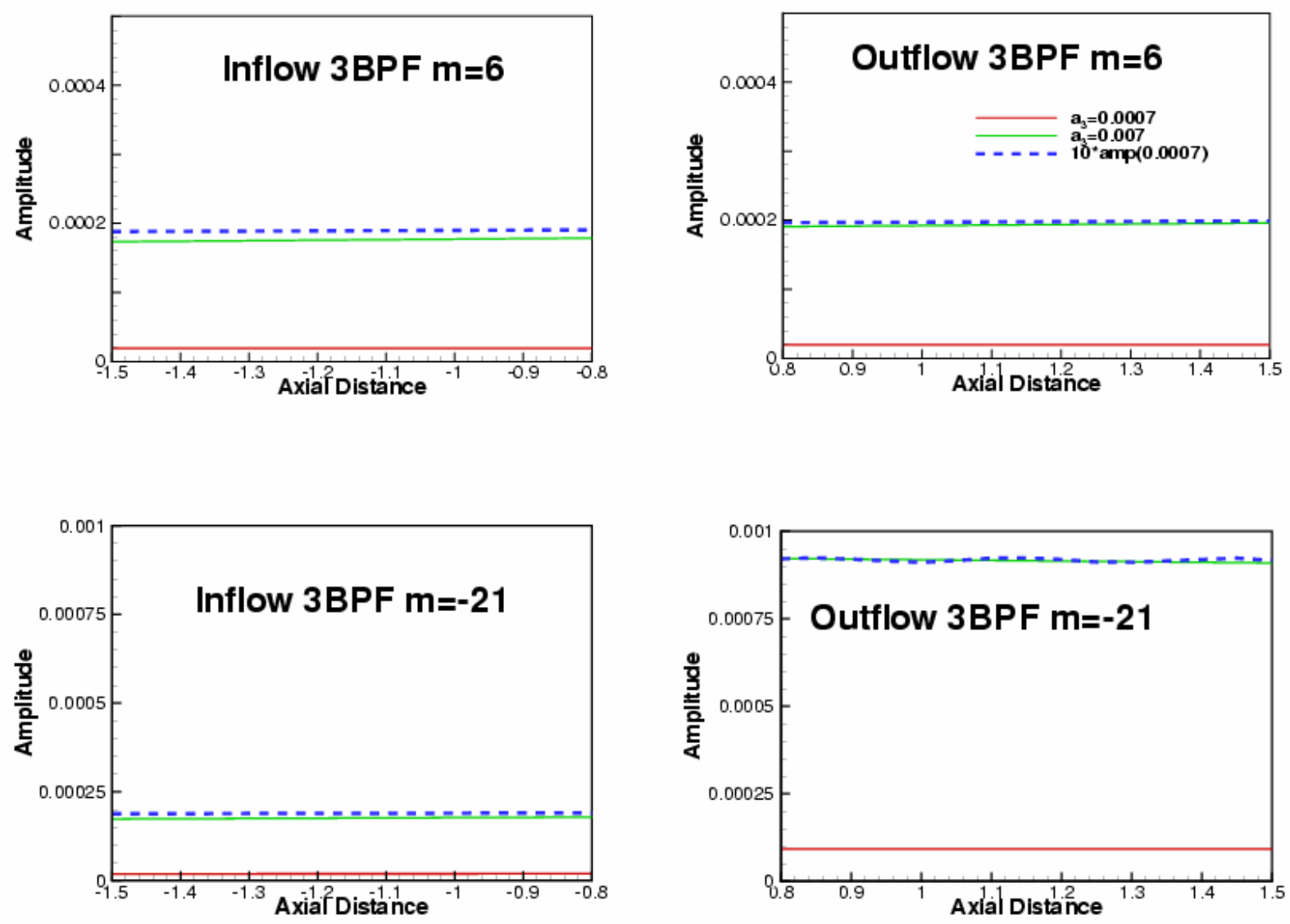

Figure 6(b). Single frequency excitation: linear behavior at 3BPF 

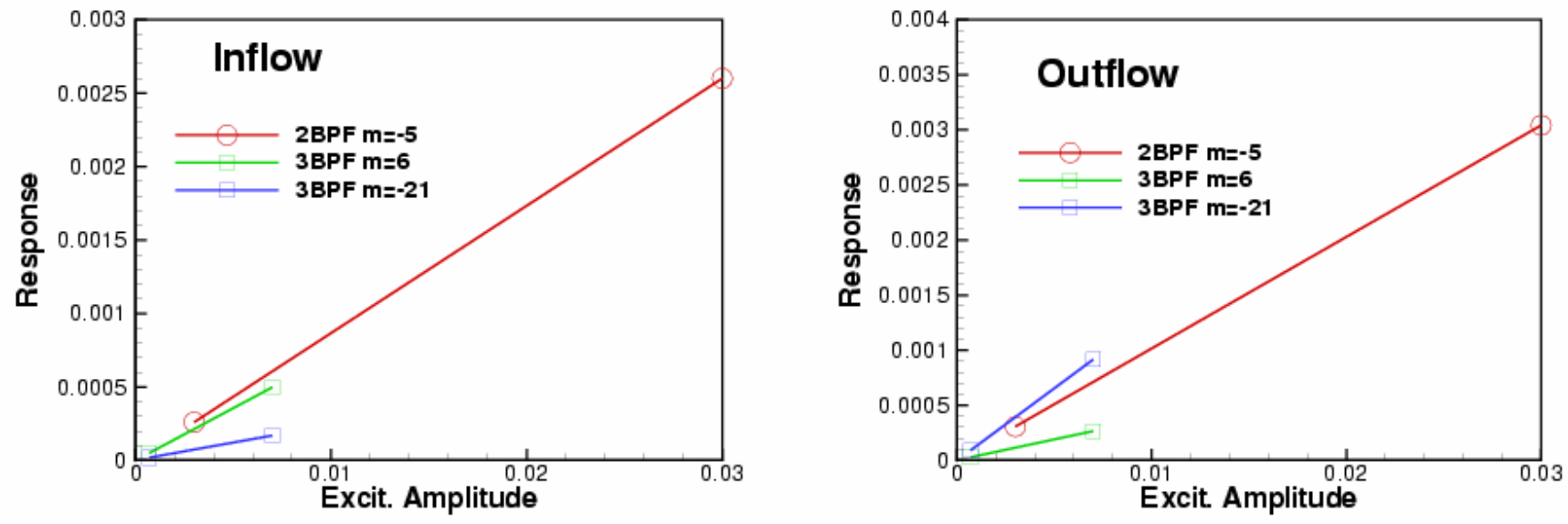

Figure 7. Single frequency excitation: excitation amplitude and acoustic response of propagating modes 

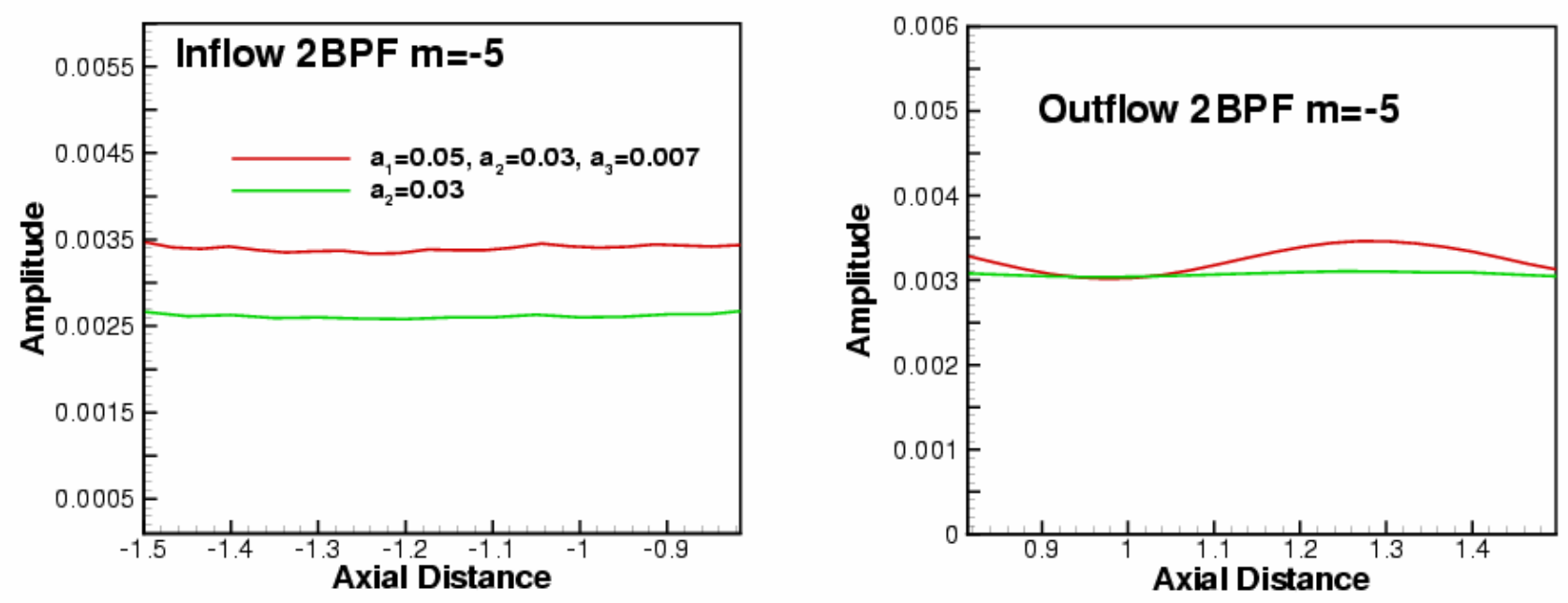

Figure 8(a). Multi-frequency excitation: Propagating mode amplitudes at 2BPF
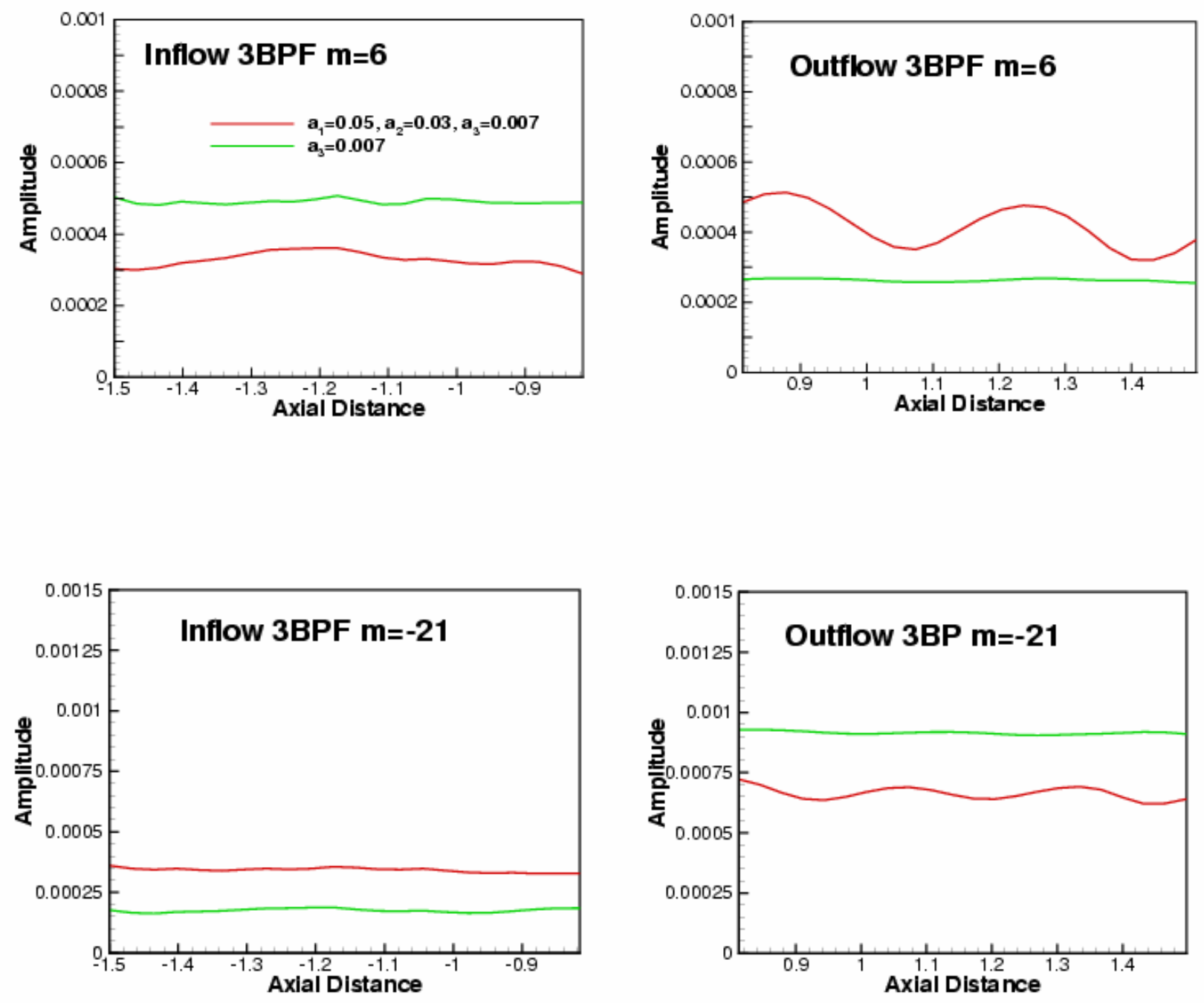

Figure 8(b). Multi-frequency excitation: Propagating modes at 3BPF 

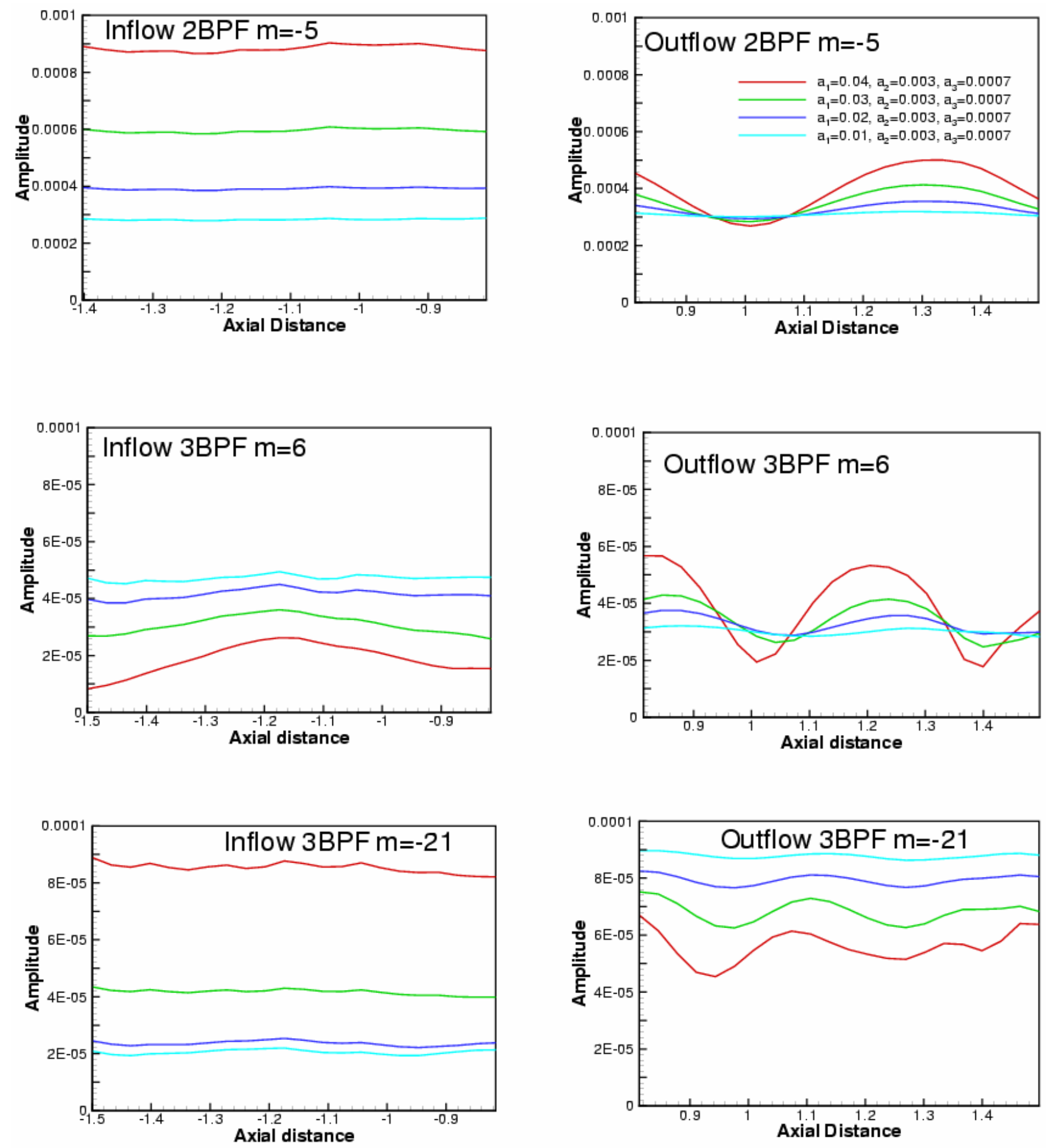

Figure 9. Multi-frequency excitation: propagating mode amplitudes 

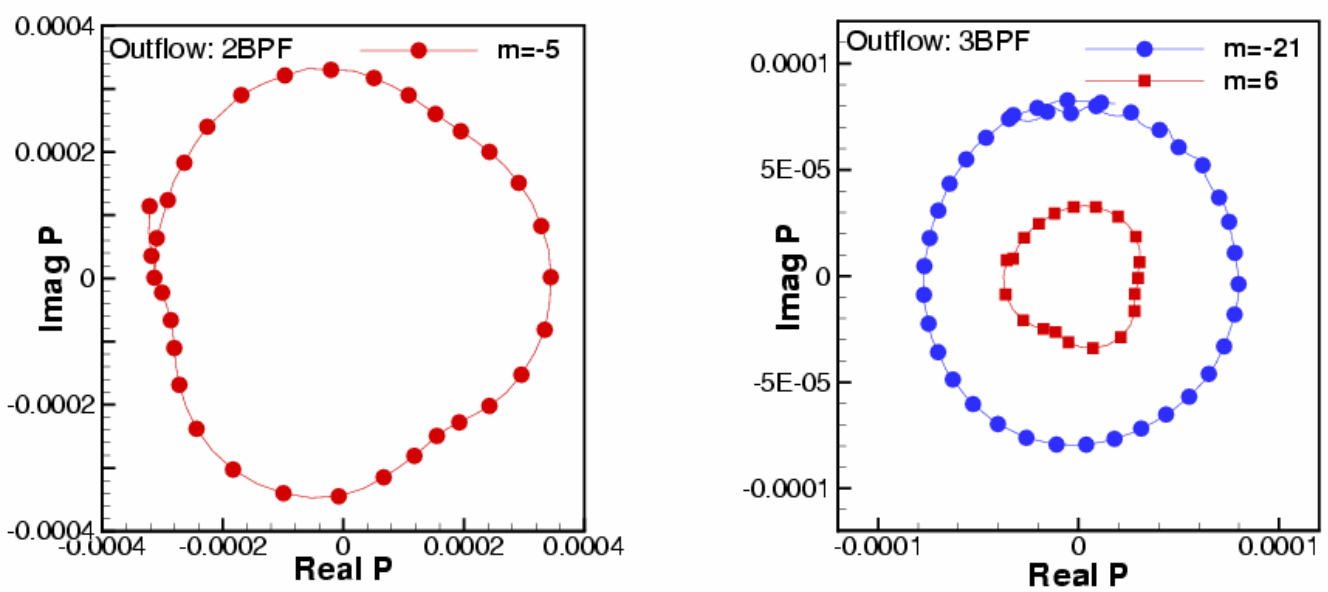

Figure 10. Multi-frequency excitation: Complex pressures of propagating modes, $a_{1}=0.02, a_{2}=0.003, a_{3}=0.0007$ 

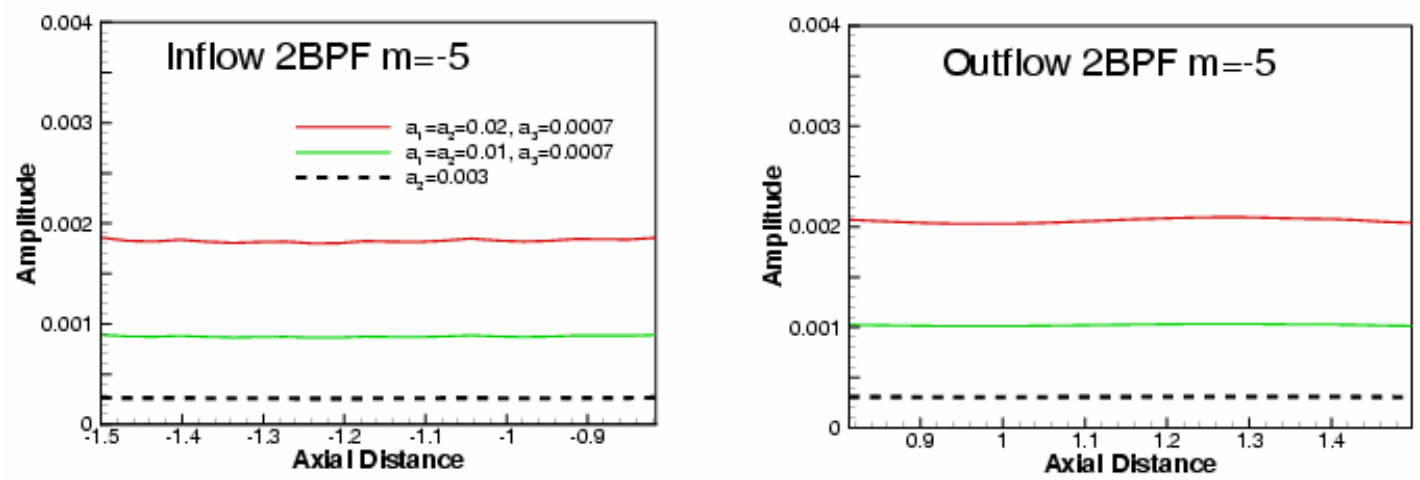

Figure 11(a). Multi-frequency excitation: $a_{1}=a_{2}=0.01,0.02$, and $a_{3}=0.0007$ : 2BPF mode amplitudes
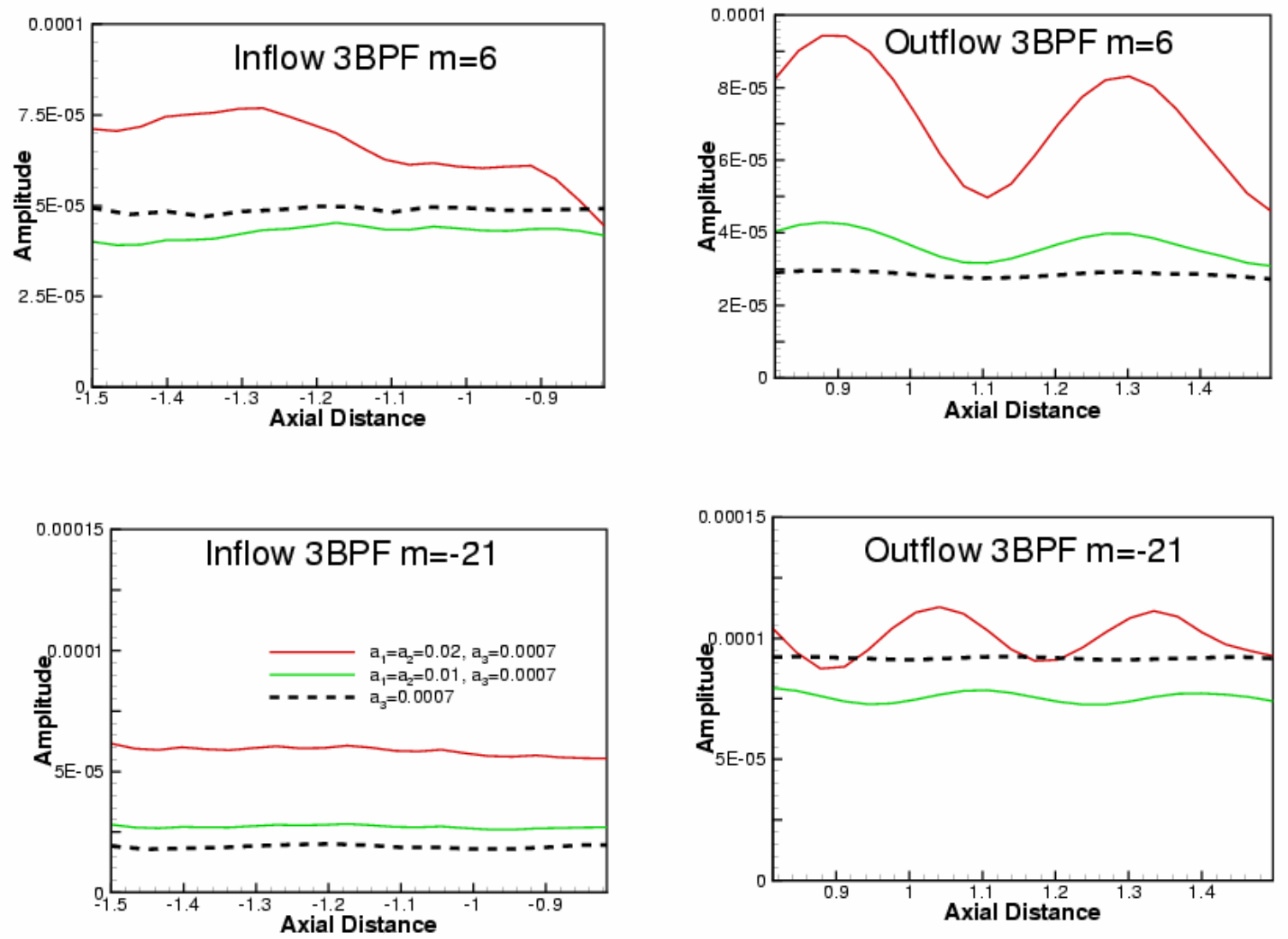

Figure 11(b). Multi-frequency excitation: $a_{1}=a_{2}=0.01,0.02$, and $a 3=0.0007$ : 3BPF mode amplitudes 

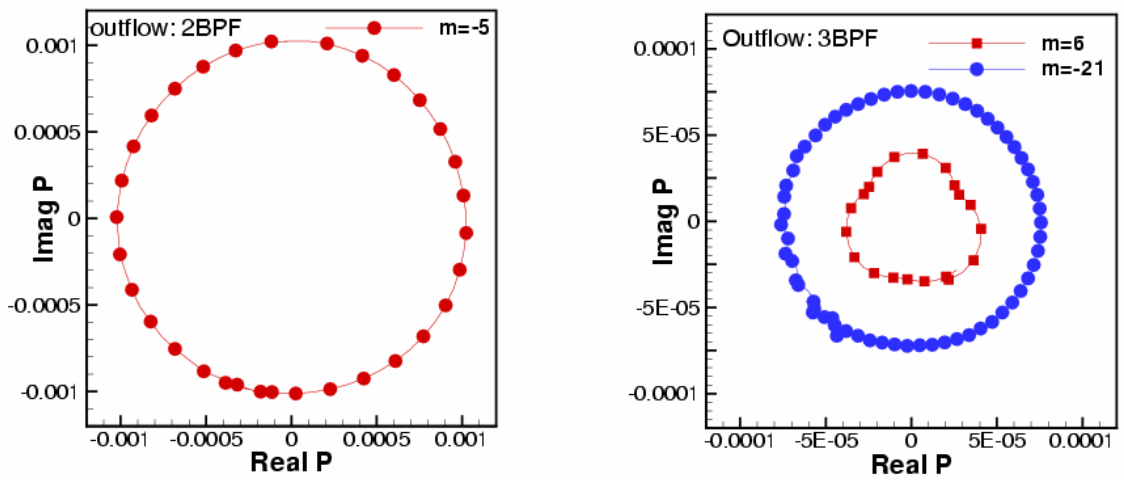

Figure 12. Multi-frequency excitation: $a_{1}=a_{2}=0.01, a_{3}=0.0007$ : complex pressure amplitudes
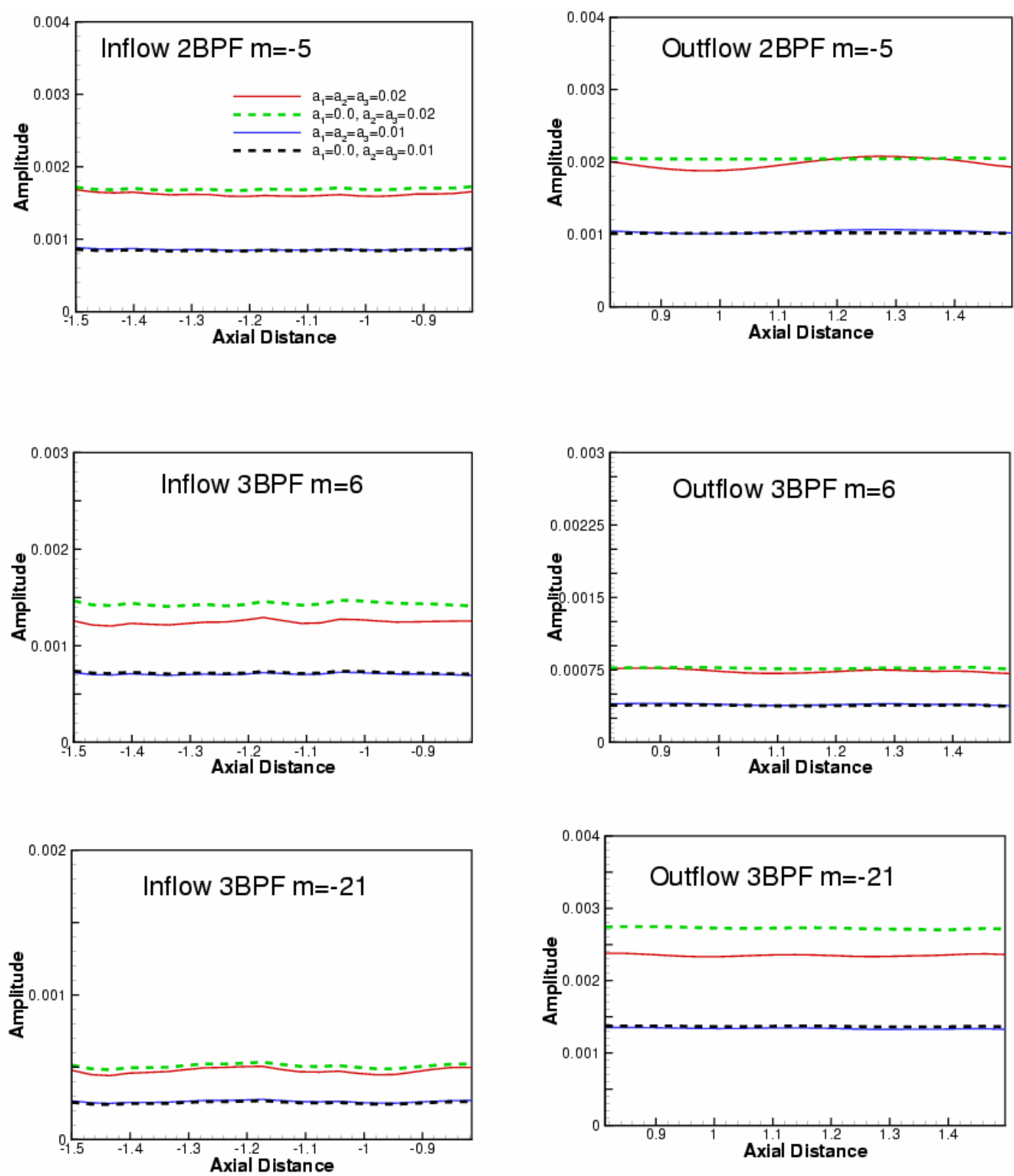

Figure 13. Linear behavior of equal amplitude excitations 


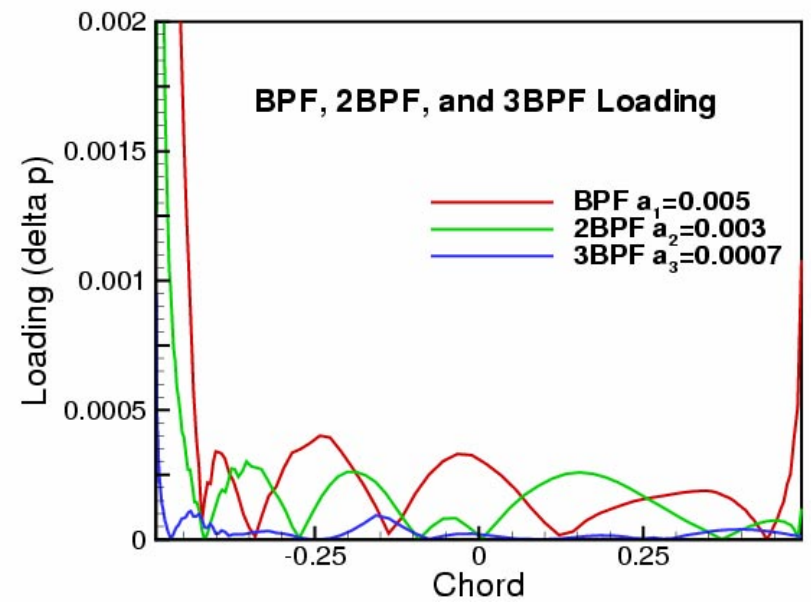

Figure 14(a). Typical harmonic loading on airfoil

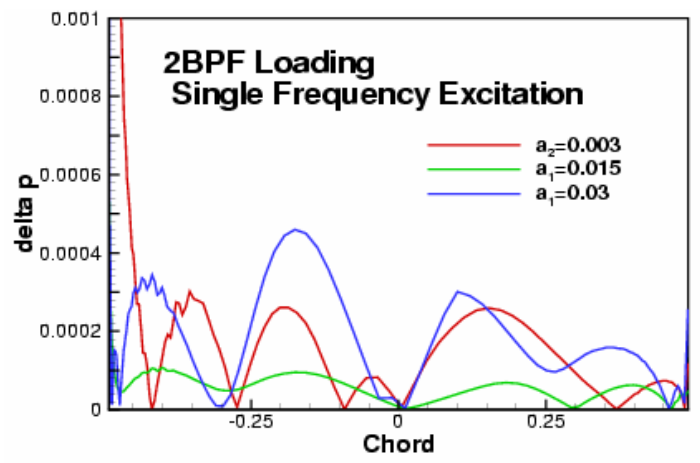

Figure 14(b). Single frequency excitation: 2nd harmonic loading

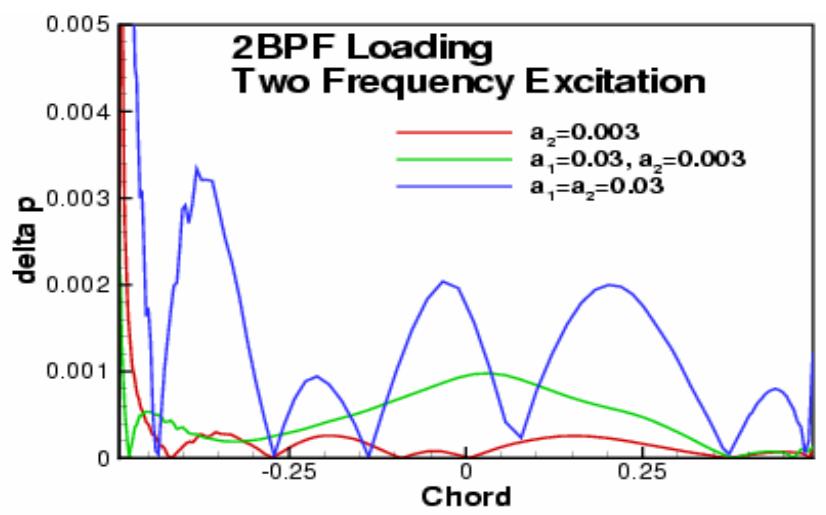

Figure 14(c). Two frequency excitation: 2nd harmonic loading 

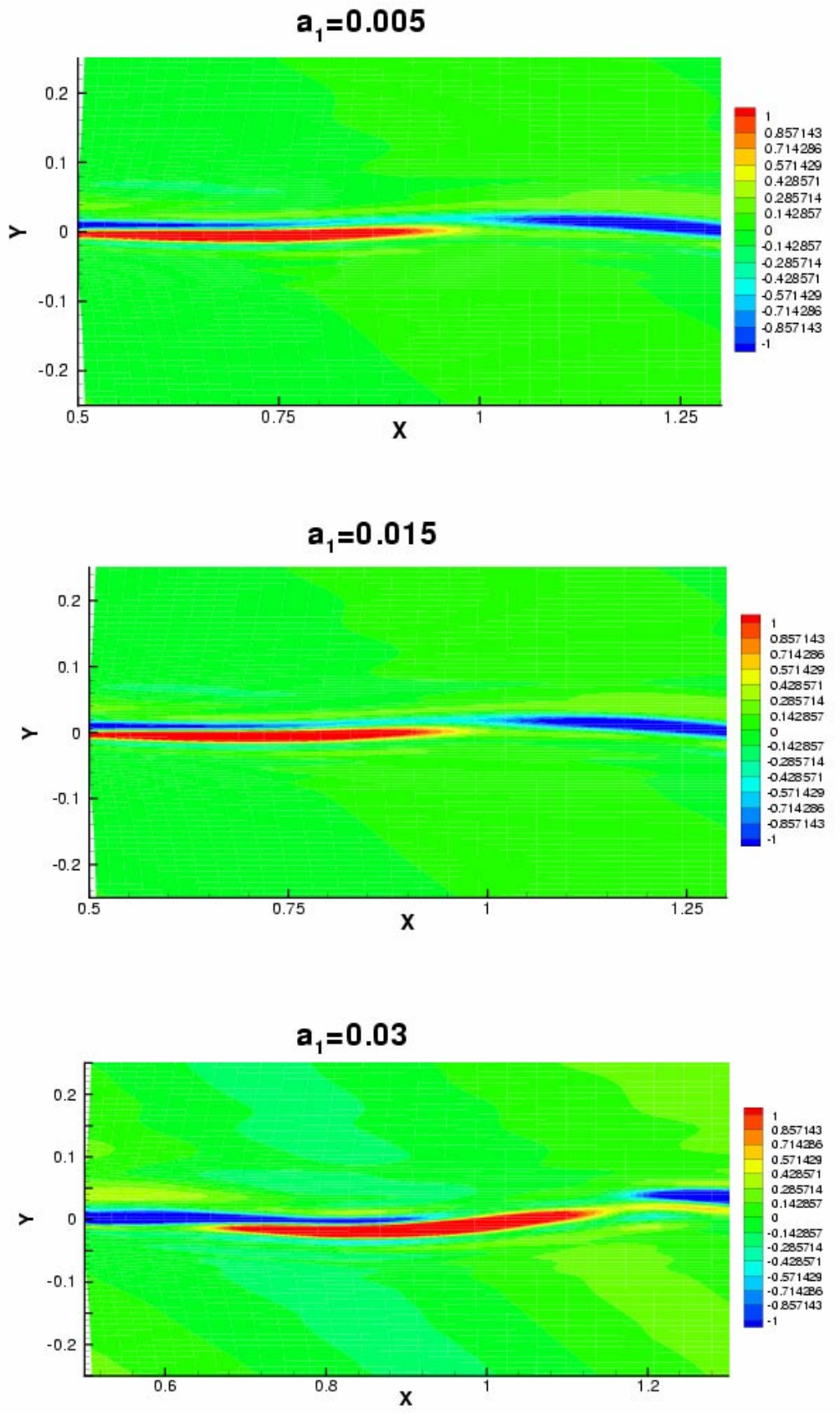

Figure 15. Airfoil wake vorticity contours 
Public reporting burden for this collection of information is estimated to average 1 hour per response, including the time for reviewing instructions, searching existing data sources, gathering and maintaining the data needed, and completing and reviewing the collection of information. Send comments regarding this burden estimate or any other aspect of this collection of information, including suggestions for reducing this burden, to Washington Headquarters Services, Directorate for Information Operations and Reports, 1215 Jefferson Davis Highway, Suite 1204, Arlington, VA 22202-4302, and to the Office of Management and Budget, Paperwork Reduction Project (0704-0188), Washington, DC 20503.

\begin{tabular}{|l|l|l}
\hline 1. AGENCY USE ONLY (Leave blank) & $\begin{array}{c}\text { 2. REPORT DATE } \\
\text { June } 2004\end{array}$ & $\begin{array}{c}\text { 3. REPORT TYPE AND DATES COVERED } \\
\text { Final Contractor Report }\end{array}$
\end{tabular}

\section{TITLE AND SUBTITLE}

Computed Linear/Nonlinear Acoustic Response of a Cascade for Single/Multi Frequency Excitation

\section{AUTHOR(S)}

M. Nallasamy, R. Hixon, and S. Sawyer

\section{FUNDING NUMBERS}

WBS-22-781-30-09

NAS3-00145

8. PERFORMING ORGANIZATION REPORT NUMBER

E-14584

QSS Group, Inc.

21000 Brookpark Road

Cleveland, Ohio 44135

10. SPONSORING/MONITORING AGENCY REPORT NUMBER

National Aeronautics and Space Administration

Washington, DC 20546-0001

NASA CR - 2004-213110

AIAA-2004-2998

\section{SUPPLEMENTARY NOTES}

Prepared for the Tenth Aeroacoustics Conference cosponsored by the American Institute of Aeronautics and Astronautics and the Confederation of European Aerospace Societies, Manchester, United Kingdom, May 10-12, 2004. M. Nallasamy, QSS Group, Inc., Cleveland, Ohio 44135; R. Hixon, University of Toledo, Toledo, Ohio 43606; and S. Sawyer, University of Akron, Akron, Ohio 44325. Project Manger, E. Envia, Structures and Acoustics Division, NASA Glenn Research Center, organization code 5940, 216-433-8956.

\begin{tabular}{|l|l} 
12a. DISTRIBUTION/AVAILABILITY STATEMENT & 12b. DISTRIBUTION CODE
\end{tabular}

Unclassified - Unlimited

Subject Categories: 01 and 71

Distribution: Nonstandard

Available electronically at http://gltrs.grc.nasa.gov

This publication is available from the NASA Center for AeroSpace Information, 301-621-0390.

13. ABSTRACT (Maximum 200 words)

This paper examines mode generation and propagation characteristics of a 2-D cascade due to incident vortical disturbances using a time domain approach. Full nonlinear Euler equations are solved employing high order accurate spatial differencing and time marching techniques. The solutions show the generation and propagation of mode orders that are expected from theory. Single frequency excitations show linear response over a wide range of amplitudes. The response for multi-frequency excitations tend to become nonlinear due to interaction between frequencies and self interaction.

\section{SUBJECT TERMS}

Aeroacoustics; Fan noise

17. SECURITY CLASSIFICATION OF REPORT

Unclassified

\section{SECURITY CLASSIFICATION OF THIS PAGE Unclassified}

15. NUMBER OF PAGES

25

16. PRICE CODE

20. LIMITATION OF ABSTRACT

SECURITY CLASSIFICATION OF ABSTRACT

Unclassified 

